\title{
Bioinformatics analysis of laryngeal squamous cell carcinoma: Seeking key candidate genes and pathways
}

\author{
Jinhua Ma ${ }^{1}$, Xiaodong Hu ${ }^{1}$, Baoqiang Dai ${ }^{1}$, Qiang Wang ${ }^{1}$, Hongqin Wang $^{\text {Corresp. } 1}$ \\ ${ }^{1}$ Department of Otolaryngology, Cangzhou Central Hospital, Cangzhou, Hebei, China \\ Corresponding Author: Hongqin Wang \\ Email address: hongqinwang0317@126.com
}

Background. Laryngeal squamous cell carcinoma (LSCC) is the second most aggressive head and neck squamous cell carcinoma. Although much work has been done to optimize its treatment, patients with LSCC still have poor prognosis. Therefore, figuring out differentially expressed genes (DEGs) contained in the progression of LSCC and employing them as potential therapeutic targets or biomarkers for LSCC is extremely meaningful.

Methods. Overlapping DEGs were screened from two standalone Gene Expression Omnibus (GEO) datasets, and Gene Ontology (GO) and Kyoto Encyclopedia of Genes and Genomes (KEGG) pathway enrichment analyses were performed. By applying STRING and Cytoscape, a protein-protein network (PPI) was built, and module analysis was carried out. The hub genes were selected by maximal clique centrality (MCC) with the CytoHubba plugin of Cytoscape. UALCAN and GEPIA data were examined to validate the gene expression findings. Moreover, the connection of the hub genes with LSCC patient overall survival was studied employing The Cancer Genome Atlas. Then, western blot, qRT-PCR, CCK-8, wound healing and transwell assays were bring to use for further verify the key genes.

Results. A total of 235 DEGs were recorded, including 83 upregulated and 152 downregulated genes. A total of nine hub genes that displayed a high degree of connectivity were selected. UALCAN and GEPIA databases verified that these genes were highly expressed in LSCC tissues. High expression of the SPP1, SERPINE1 and MMP1 genes was connected to worse prognosis in patients with LSCC, according to the GEPIA online tool. Western blot and qRT-PCR testify SPP1, SERPINE1 and MMP1 were upregulated in LSCC cells. Inhibition of SPP1, SERPINE1 and MMP1 suppressed cell proliferation, invasion and migration.

Conclusion. The work here identified effective and reliable diagnostic and prognostic molecular biomarkers by unified bioinformatics analysis and experimental verification, indicating novel and necessary therapeutic targets for LSCC. 


\section{Bioinformatics analysis of laryngeal squamous cell}

\section{2 carcinoma: Seeking key candidate genes and pathways}

3 Jinhua $\mathrm{Ma}^{1}$, Xiaodong $\mathrm{Hu}^{1}$, Baoqiang Dai ${ }^{1}$, Qiang Wang ${ }^{1}$, Hongqin Wang ${ }^{1}$

$4{ }^{1}$ Department of Otolaryngology, Cangzhou Central Hospital, Cangzhou, 061001 China.

5

6 Corresponding Author:

7 Hongqin Wang ${ }^{1}$

8 Department of Otolaryngology, Cangzhou Central Hospital, Cangzhou, 061001 China.

9 Email address: hongqinwang0317@126.com 


\section{Abstract:}

Background. Laryngeal squamous cell carcinoma (LSCC) is the second most aggressive head and neck squamous cell carcinoma. Although much work has been done to optimize its treatment, patients with LSCC still have poor prognosis. Therefore, figuring out differentially expressed genes (DEGs) contained in the progression of LSCC and employing them as potential therapeutic targets or biomarkers for LSCC is extremely meaningful.

Methods. Overlapping DEGs were screened from two standalone Gene Expression Omnibus (GEO) datasets, and Gene Ontology (GO) and Kyoto Encyclopedia of Genes and Genomes (KEGG) pathway enrichment analyses were performed. By applying STRING and Cytoscape, a protein-protein network (PPI) was built, and module analysis was carried out. The hub genes were selected by maximal clique centrality (MCC) with the CytoHubba plugin of Cytoscape. UALCAN and GEPIA data were examined to validate the gene expression findings. Moreover, the connection of the hub genes with LSCC patient overall survival was studied employing The Cancer Genome Atlas. Then, western blot, qRT-PCR, CCK-8, wound healing and transwell assays were bring to use for further verify the key genes.

Results. A total of 341 DEGs were recorded, including 205 upregulated and 136 downregulated genes. A total of nine hub genes that displayed a high degree of connectivity were selected. UALCAN and GEPIA databases verified that these genes were highly expressed in LSCC tissues. High expression of the SPP1, SERPINE1 and MMP1 genes was connected to worse prognosis in patients with LSCC, according to the GEPIA online tool. Western blot and qRTPCR testify SPP1, SERPINE1 and MMP1 were upregulated in LSCC cells. Inhibition of SPP1, SERPINE1 and MMP1 suppressed cell proliferation, invasion and migration.

Conclusion. The work here identified effective and reliable diagnostic and prognostic molecular biomarkers by unified bioinformatics analysis and experimental verification, indicating novel and necessary therapeutic targets for LSCC.

Key words: laryngeal squamous cell carcinoma; bioinformatics analysis; GO; KEGG 


\section{Introduction}

As the second most aggressive head and neck squamous cell carcinoma (HNSCC), the incidence of laryngeal squamous cell carcinoma (LSCC) is rapidly increasing, and in 2018, approximately 13,150 new cases were expected to be found in the United States, of which approximately 3710 would die due to the disease(Jemal et al. 2007; Patel et al. 2019). Although good outcomes can be achieved for those with LSCC through the use of accurate surgery and chemoradiotherapy, $30 \%$ of patients experience disease recurrence or distant metastasis that can lead to death(Johnson et al. 2019). Moreover, the mortality of patients with more advanced LSCC tumours (stage III and IV) is higher(Hermida-Prado et al. 2019). So it is significant and urgent to identify key biomarkers and novel therapeutic targets in LSCC.

Cancer is a heterogeneous disease that is characterized by many kinds of gene aberrations, and this is also the case for LSCC(Shen et al. 2019). However, the mechanisms of LSCC development are not completely understood. With the continuous advances in microarray technology and bioinformatics analysis, gene chip technology plays a significant role in exploring tumour gene expression profiles and identifying the DEGs and functional pathways associated to tumorigenesis and prognosis(Tinker et al. 2006). In this work, the microarray data of two gene expression profiles were obtained, and DEGs were recognized between cancerous and noncancerous tissues, succeeded by deeper evaluation with Gene Ontology (GO) and Kyoto Encyclopedia of Genes and Genomes (KEGG) pathway analyses. Moreover, a protein-protein interaction (PPI) network of DEGs was constructed, and the CytoHubba plugin of Cytoscape was used to identify the hub genes. Additionally, the overlapping gene expression between healthy and tumour tissues was confirmed by the UALCAN and GEPIA online databases. The following nine DEGs were selected for further analysis: MMP9, SPP1, SERPINE1, MMP1, MMP13, MMP3, CXCL8, OSM, and COL1A1. GEPIA was played to evaluate the prognosis of the mentioned hub genes with disease prognosis and showed that SPP1, SERPINE1 and MMP1 were 
80

correlated with worse survival. Then, we demonstrated by western blot and qRT-PCR that SPP1, SERPINE1 and MMP1 were upregulated in LSCC cells. Inhibition of SPP1, SERPINE1 and MMP1 could suppress cell proliferation, invasion and migration. In summary, the bioinformatic study presented here offers some promising biomarkers connected to the development and prognosis of patients with LSCC.

\section{Materials and Methods}

\section{DEGs identification in LSCC}

We obtained the gene expression profiles of LSCC from the GEO database (https://www.ncbi.nlm.nih.gov/geo/)(Barrett et al. 2013). The raw gene expression profile datasets GSE59102 and GSE107591 were obtained from that database. The platform for GSE59102 is GPL6480, Agilent-014850 Human Genome Microarray 4x44K G4112F (Probe Name version), including 13 normal tissues and 29 tumour tissues. The platform for GSE107591 is GPL6244, HuGene-1_0-st] Affymetrix Human Gene 1.0 ST Array, containing 23 normal and 24 tumour tissues. The DEGs between cancerous and noncancerous tissues were detected by GEO2R (http://www.ncbi.nlm.nih.gov/geo/geo2r) with the criteria of logFC (fold change) $>1$ and adjusted P-value $<0.01$, which were thought to indicate clearly differential expression(Davis $\&$ Meltzer 2007). The next step was to use the online Venn software to identify the intersection of DEGs between the two datasets.

\section{KEGG and GO enrichment analyses of DEGs}

We used the Database for Annotation, Visualization and Integrated Discovery (DAVID, http://david.abcc.ncifcrf.gov/) online tool to study the roles of the identified DEGs and put into effect functional and pathway enrichment analysis(Huang et al. 2007). Kyoto Encyclopedia of 
104

105

106

107

Genes and Genomes (KEGG) (http://www.kegg.jp), an integrated database, was applied to determine the high-level functions and the biological interpretation of genome sequences and other high-throughput data(Kanehisa et al. 2016). The Gene Ontology (GO) (http://www.geneontology.org) project is a primary bioinformatics tool for annotating genes and analysing the biological processes of the genes and includes the biological process (BP), cellular component (CC), and molecular function (MF)(Ashburner et al. 2000). P-value $<0.05$ was thought to refer a important difference in statistic.

\section{PPI network construction and module analysis}

A PPI network of DEGs was foreseen by the Search Tool for the Retrieval of Interacting Genes/Proteins (STRING) online database (version 11.0; http://string-db.org)(Szklarczyk et al. 2015). Based on the STRING online tool, PPIs of the DEGs were constructed with a confidence score $>0.4$, we exported the results as a simple tabular text. Cytoscape software version 3.7.1 (www.cytoscape.org) is an open source bioinformatics software platform for visualizing molecular interaction networks. Subsequently, the PPI network was visualized by means of Cytoscape software(Holmås et al. 2019). The most significant module in that network was detected by the Molecular Complex Detection (MCODE) (version 1.4.2) plug-in of Cytoscape(Bandettini et al. 2012). The selection standards: MCODE score $>5$; degree cut-off $=$ 2 ; node score cut-off $=0.2 ;$ max depth $=100$; and $\mathrm{k}$-score $=2$. Afterward, $\mathrm{KEGG}$ and GO analyses of the genes in the PPI were performed by DAVID.

\section{Hub gene selection and analysis}

The CytoHubba plug-in of Cytoscape is an application that contains several topological algorithms for ranking nodes in a PPI network by the network characteristics. In this work, 
128

129

130

131

132

133

134

135

136

137

138

139

140

141

142

143

144

145

146

147

148

149

150

151

maximal clique centrality (MCC) was selected to explore the top 9 hub genes among the 12 available computing methods(Chin et al. 2014). Moreover, the UALCAN (http://ualcan.path.uab.edu/) and GEPIA (http://gepia.cancer-pku.cn/) online databases were resorted to validate gene expression. UALCAN and GEPIA are internet tools that provide a straightforward way to investigate publicly available cancer transcriptome data, including TCGA (The Cancer Genome Atlas)(Chandrashekar et al. 2017; Tang et al. 2017). Moreover, the GEPIA database was applied to survival analysis of the hub genes. P-value $<0.05$ was considered as inportant in statistic.

\section{Cell culture and cell transfection}

The human LSCC cell lines Hep2 and LSC-1 (Bluefbio, China) and human laryngeal epithelial cells (HLECs; Lifeline, United States) were cultured in Dulbecco's modified Eagle's medium (DMEM) containing 10\% foetal bovine serum, $100 \mu / \mathrm{mL}$ streptomycin and $100 \mu / \mathrm{mL}$ penicillin, the culture conditions were $37^{\circ} \mathrm{C}$ and $5 \% \mathrm{CO}_{2}$. All cells were passaged 3 to 4 times before use(Wang et al. 2018).

The siRNA-SPP1, siRNA-SERPINE1 and siRNA-MMP1 that were transfected into Hep2 and LSC-1 cell lines by Lipofectamine 2000 were obtained from GeneCreate (China) in accordance with the instuctions of manufacturer. Hep2 and LSC-1 cells were cultured in DMEM at least $24 \mathrm{~h}$ and before transfection, they also need to washed with phosphate-buffered saline (PBS, pH 7.4) before transfection(Liu et al. 2019).

\section{Western blot}

Total protein isolated from Hep2 and LSC-1 cells and HLECs were loaded into sodium dodecyl sulfate polyacrylamide gel electrophoresis (SDS-PAGE) gels and transferred to 
152 polyvinylidene fluoride (PVDF) membranes. The PVDF was hindered with 5\% skim milk at $15337^{\circ} \mathrm{C}$ for $90 \mathrm{~min}$. Next, the PVDF membrane was incubated with SPP1, SERPINE1 or MMP1 154 rabbit polyclonal antibodies (Proteintech, United States) and $\beta$-actin rabbit polyclonal antibodies 155 (ABclonal, United States) at $4^{\circ} \mathrm{C}$ overnight. And the PVDFwas rinsed with PBST for 10 min and 156 repeated three times. Then, the PVDF was incubated with horseradish peroxidase-labelled goat 157 anti-rabbit IgG secondary antibody (Jackson, United States) at $37^{\circ} \mathrm{C}$ for $60 \mathrm{~min}$. The PVDF was 158 rinsed with PBST for $10 \mathrm{~min}$ and repeated three times. Then, the immunoactivity was detected 159 by optical luminometry(Mishra et al. 2017).

qRT-PCR

To isolate total RNA from Hep2 cells, LSC-1 cells and HLECs, we used TRIzol reagent

163

164

(TAKARA, Japan) according to the instructions. The conditions of reverse transcription reaction can be noticed: $25^{\circ} \mathrm{C}$ for $10 \mathrm{~min}, 50{ }^{\circ} \mathrm{C}$ for $30 \mathrm{~min}$ and $85{ }^{\circ} \mathrm{C}$ for $5 \mathrm{~min}$. Detection using the fluorescence quantitative PCR kit. The conditions of fluorescence quantitative PCR were as follows: $95^{\circ} \mathrm{C}$ for $5 \mathrm{~min}, 95^{\circ} \mathrm{C}$ for $10 \mathrm{~s}, 60^{\circ} \mathrm{C}$ for $30 \mathrm{~s}$, a total of 40 cycles. The solubility curve temperature range was set at $60-95^{\circ} \mathrm{C}$, and three replicate wells were prepared for each specimen. SPP1, SERPINE1 and MMP1 used $\beta$-actin as internal factors(Wilhelm \& Pingoud 2003). The qRT-PCR results were determined by the $2^{-\Delta \Delta C t}$ approach, and the primer sequences are listed in Table 1.

\section{CCK-8 assay}

To determine the proliferation of Hep2 and LSC-1 cells, we used a CCK-8 assay. We incubated the cells in 96-well culture plates and the inoculation density was $3 * 10^{5}$. For cell transfection, the cells were cultured overnight. After transfection for $48 \mathrm{~h}, 10 \mathrm{~mL}$ of CCK-8 
176

177

178

179

180

181

182

183

184

185

186

187

188

solution was added to each well, and the cells were incubated at $37^{\circ} \mathrm{C}$ for another $60 \mathrm{~min} .490$ $\mathrm{nm}$ was used as the absorbance of the solutions, and the absorbance of the solutions was detected by a Smart Microplate Reader (SMR)16.1(Ma et al. 2017).

\section{Transwell migration assay}

For cell migration tests of Hep2 and LSC-1 cells, Transwell chambers with a polycarbonate membrane were used. In the upper chambers, Hep2 and LSC-1 cells were incubated in serumfree DMEM, and 10\% FBS was out to the lower chambers. After $10 \mathrm{~h}$, the Hep2 and LSC-1 cells in the upper chambers were removed, and the cells in the lower chambers were dyed with crystal violet at $25^{\circ} \mathrm{C}$ for $1 \mathrm{~min}$. A light microscope was used to observe and count the cells in 5 randomly selected fields.

\section{Wound healing assay}

Hep2 and LSC-1 cells were inoculated into the 6-well plates. When cells were at 90\%$100 \%$ confluence, wounds of uniform width were created by slowly pulling a $10 \mu \mathrm{L}$ pipette perpendicular to the bottom of the 6 -well plate ( 3 wounds/well). Then, the cells were rinsed with PBS 3 times to remove floating cells, and incubated in serum-free DMEM to inhibit cell proliferation and division. At $0 \mathrm{~h}$ and $24 \mathrm{~h}$ after wounding and culture, the migration distance of cells in the wound area was observed under a microscope, and several different fields of view were randomly selected for photographing(He et al. 2020). The experiment was repeated 3 times.

\section{Statistical analysis}

Statistical Product and Service Solutions (SPSS) 25.0 software was ran for analysis in 
199 200

201

202

203

204

205

206

207

208

209

210

211

212

213

214

215

216

217

218

219

220

221

statistic. The t-test was applied to numerical data, and $\mathrm{P}<0.05$ indicated the significance level.

\section{Results}

\section{DEGs identification in LSCC}

Before identifying DEGs in LSCC, the microarray was standardized. We identified 3,359 DEGs in GSE59102 and 444 DEGs in GSE107591. The overlap between the 2 datasets included 341 genes (Fig. 1), including 205 downregulated genes and 136 upregulated ones between LSCC tissues and control tissues.

\section{KEGG and GO enrichment analyses of DEGs}

GO and KEGG pathway enrichment analyses were performed in DAVID (Table 2) to study the biological classification of the DEGs. The BP category outcomes of the GO analysis outcomes expressed that the DEGs were markedly associated with extracellular matrix organization, cell adhesion, the collagen catabolism pathway and positive regulation of cellsubstrate adhesion. Within the CC categories, the DEGs were markedly linked with the extracellular region, extracellular matrix and proteinaceous extracellular matrix. Among the MF categories, the DEGs were significantly enriched in heparin binding and extracellular matrix structural constituents. In addition, KEGG signalling pathway analysis illustrated that the DEGs were pivotal in the following pathways: 'ECM-receptor interaction', 'drug metabolismcytochrome P450', 'focal adhesion', 'PI3K-Akt signaling pathway' and 'complement and coagulation cascades'.

\section{PPI network construction and remarkable module identification}


222

223

224

225

226

227

228

229

230

231

232

233

234

235

236

237

238

239

240

241

242

243

244

245

246

The STRING database was used to predict the interactions among the DEGs with a

combined score $>0.4$ at the protein level. The PPI network was built with Cytoscape software and included 176 nodes and 371 edges (Fig. 2A). Additionally, the hubs of the PPI network module were obtained by MCODE and consisted of 9 nodes and 34 edges (Fig. 2B). The

functional analyses of genes contained with the modules were identified by running DAVID. The outcomes indicated that the genes of this module were highly abundant in condensed nuclear chromosome outer kinetochore, ATP binding and ATP-dependent microtubule motor activity, plus-end-directed (Table 3). To more deeply investigate the top 9 hub genes, we used the cytoHubba plug-in of Cytoscape in the above PPI using the MCC method. The hub genes MMP9, SPP1, SERPINE1, MMP1, MMP13, MMP3, CXCL8, OSM, and COL1A1 were used for further analysis. The names, abbreviations and synonyms for these hub genes can be seen in Table 4.

High Expression of SPP1, SERPINE1, and MMP1 in LSCC and their Association with Poor Prognosis

Tools in the UALCAN and GEPIA databases were used to evaluate the expression levels of these 9 genes in LSCC. Both databases confirmed that the expression of MMP9, SPP1, SERPINE1, MMP1, MMP13, MMP3, CXCL8, OSM, and COL1A1 showed obvious differences in LSCC samples and healthy samples, which was in accordance with the results discussed above (Fig. 3). Using the GEPIA database to study the relationship between gene expression and patient survival, we found that only SPP1, SERPINE1 and MMP1 were obviously connected with the overall survival of patients with LSCC (Fig. 4). Therefore, we verified the expression of SPP1, SERPINE1 and MMP1 in LSCC cells by western blot (Fig. 5A-D) and qRT-PCR (Fig. 5E). The outcomes indicated that SPP1, SERPINE1 and MMP1 were highly expressed in HEP2 and LSC-1 cells. These results were consistent with the bioinformatics analysis. 
248

249

250

251

252

253

254

255

256

257

258

259

260

261

262

263

264

265

266

267

268

269

270

\section{Downregulation of SPP1, SERPINE1, and MMP1 Expression Inhibited LSCC Cell} Proliferation In Vitro

To further verify the function of SPP1, SERPINE1 and MMP1 in HEp-2 and LSC-1 cells, SPP1, SERPINE1 and MMP1 were knocked down in vitro. CCK-8 was performed to verify the effects of SPP1, SERPINE1 and MMP1 on HEp-2 and LSC-1 cell proliferation in vitro. HEp2 and LSC-1 cells treated with siRNA-SSP1, siRNA-SERPINE1, siRNA-MMP1 and siRNA-NC were cultured and then subjected to CCK- 8 assays. The results showed that the growth rate of HEp-2 and LSC-1 cells was significantly inhibited after knockdown of SPP1, SERPINE1 and MMP1 (Fig. 6).

\section{Downregulation of SPP1, SERPINE1, and MMP1 Expression Inhibited LSCC Cell Migration and Invasion In Vitro}

Invasion and metastasis are important features of tumours. Therefore, the effects of SPP1, SERPINE1, and MMP1 on migration and invasion of HEp-2 and LSC-1 cells were analysed in depth. First, transwell migration assay was performed, and the results were consistent with those of the wound healing assay. After knockdown of any of these genes, the amount of cells passing through the filter membrane to the lower chamber was decreased significantly $(\mathrm{p}<0.05$, Fig. 7AJ). Next, a wound healing assay was used to detect the cell migration capacities in the control group and the SPP1, SERPINE1, and MMP1 knockdown groups. The results showed that the migration distance of cells in the SPP1, SERPINE1, and MMP1 knockdown groups was shorter when comparing with that in control set after $24 \mathrm{~h}(\mathrm{p}<0.05$, Fig. 7K-L).

\section{Discussion}


Tobacco use, alcohol consumption, and rising incidences of viral infections, such as human

272

273

274

275

276

277

278

279

280

281

282

283

284

285

286

287

288

289

290

291

292

293

294

295

296

papillomavirus (HPV) infection, have been considered the principal aetiological factors of the pathogenesis of LSCC(D'Souza et al. 2017; Gheit et al. 2014). However, the development of LSCC is a sophisticated biological programme. For the past few years, many biomarkers have been applied for the diagnosis and treatment of LSCC(Cossu et al. 2019). Various anti-LSCC mechanisms have also been identified(Chrysovergis et al. 2019). At the same time, few studies have been performed at the multigene level. Studies at the multigene level can contribute to exploring cancer pathogenesis.

In this work, the microarray datasets GSE59102 and GSE107591 were selected to confirm DEGs between cancerous and noncancerous tissues, with 36 healthy and 53 tumour tissues in total. The combined outcomes unveiled 235 generally changed genes, including 83 upregulated and 152 downregulated DEGs, that were obviously expressed in LSCC tumour specimens $(\mathrm{P}<$ 0.05, $|\log \mathrm{FC}|>2$ ). According to the DEGs to bioinformatics analysis, containing $\mathrm{GO}$ enrichment, KEGG pathway, PPI network and survival analyses, unveiled that genes related to LSCC and pathways may play a vital function in the cancer initiation and development.

In the GO term enrichment analysis, the DEGs were importantly connected with the terms 'extracellular matrix organization', 'extracellular region' and 'heparin binding'. KEGG pathway analysis indicated that the roles of the DEGs were enriched in 'ECM-receptor interaction', 'drug metabolism-cytochrome P450', 'focal adhesion', 'PI3K-Akt signalling pathway' and 'complement and coagulation cascades'. The extracellular matrix (ECM) is a sophisticated and dynamic molecular network that surrounds tumour cells and plays vial functions in tumour progression and metastasis(Kim et al. 2016; Xu et al. 2017). As tumour cells proliferate, the surrounding ECM experiences important architectural alterations through a dynamic interplay between the microenvironment and resident cells(Grossman et al. 2016). In addition, a recent study recorded that cytochrome P450 inhibited the activity of the metabolic enzymes CYP2C9*2 and CYP2C $9 * 3$, which could directly control tumorigenesis by reducing epoxyeicosatrienoic 
297

298

299

300

301

302

303

304

305

306

307

308

309

310

311

312

313

314

315

316

317

318

319

320

321

322

acid production(Hunter et al. 2015; Katiyar et al. 2017). The PI3K-Akt signalling pathway has a vital function in LSCC by suppressing cell death(Chrysovergis et al. 2019; Yang et al. 2019). P53, a tumour suppressor factor, initiates DNA repair, cell cycle arrest and apoptosis and reacts to various kinds of cancer therapies(Cui et al. 2019; Ragos et al. 2018). The changes above are connected with the findings in this study that the biological processes of the DEGs necessarily contribute to the progression of LSCC.

Furthermore, analysis showed that the most significant module from the PPI network of LSCC DEGs was connected with the cell cycle and cell metabolism. After further analysis of the DEG PPI network, 9 hub genes, MMP9, SPP1, SERPINE1, MMP1, MMP13, MMP3, CXCL8, OSM, and COL1A1, were identified, and were all obviously upregulated in LSCC tissue compared with healthy tissues. In addition, the UALCAN and GEPIA online resources were requested for further confirmation of the expression levels of these key genes in LSCC. Each database clearly demonstrated the same tendency in expression as indicated by bioinformatics analysis. Moreover, applying the data from GEPIA, it was recorded that people with LSCC with highly expressed SPP1, SERPINE1 and MMP1 had worse survival outcomes.

Matrix metalloproteinases (MMPs), which are important proteolytic enzymes, can degrade almost all ECM components and are closely related to tumour infiltration, invasion and metastasis(Grzelczyk et al. 2016). Our research shows that MMP9, MMP1, MMP13 and MMP3 are highly expressed in LSCC. In addition, a few studies have focused on the correlation between LSCC and MMP expression levels. The upregulation of MMP9 and MMP3 has been connected to metastatic progression(Matulka et al. 2019; Zhou \& Qi 2015). The increase in MMP3 levels may has a relation with the regulation of the ERK/MAPK signalling pathway by placental growth factor(Zhou \& Qi 2014). Recent works have indicated that MMP9 increases tumour resistance to anti-PD-1 antibodies(Zhao et al. 2018). A study by Krecicki T et al. showed that MMP1 and MMP13 were highly expressed in LSCC patients(Krecicki et al. 2003). Other studies demonstrated that MMP1 is highly expressed in LSCC and correlates with patient prognosis, 
323

324

325

326

327

328

329

330

331

332

333

334

335

336

337

338

339

340

341

342

343

344

345

346

347

348

349

which is consistent with our conclusions(Kalfert et al. 2014; Liu et al. 2011). In our work, MMP1 was proven to be highly expressed in LSCC cells, and inhibition of MMP1 suppressed LSCC cell proliferation, invasion and migration. These data indicate that the inhibition of MMP1 might be a bright measure to treat LSCC. The increased expression of MMP13 is also associated with metastatic progression. Immunohistochemical experiments have shown the correlation of MMP13 with TIMP1 (tissue inhibitor of MMPs), which is important in the progression of LSCC(Culhaci et al. 2004). MMPs play vital roles in the spread of malignant tumours by modulating local tumour cell invasion, distant metastasis, angiogenesis, and apoptosis(Rydlova et al. 2008). Accordingly, MMP inhibitors are still hopeful for the cure of LSCC.

SPP1, also known as osteopontin, is one of the most significantly overexpressed genes in LSCC and is closely related to LSCC progression. SPP1 is a multifunctional gene that was first reported as a biomarker in the cell epithelial transformation process(Han et al. 2019). However, reports of SPP1 in laryngeal diseases, especially LSCC, are insufficient. In cancer research, the published literature has provided a basic outline of SPP1 biofunctions in tumorigenesis and processes. In colorectal cancer, high SPP1 expression is correlated with poor survival, high TNM stage and positive venous invasion(Assidi et al. 2019). SPP1 participates in the recurrence and metastasis of prostate cancer by mediating the biological process of the Smad4/PTEN pathway(Ding et al. 2011). Additionally, SPP1 expression regulation can promote cell growth and mobility in ovarian cancer, and this course may has the relation with the $\beta 1 / \mathrm{FAK} / \mathrm{AKT}$ pathway(Zeng et al. 2018). As the main regulator of the plasminogen activator system, SERPINE1 functions prominently in controlling tumour cell migration and ECM remodelling(Pavón et al. 2016). Furthermore, SERPINE1 could induce the EMT process and improve tumour cell survival in ovarian and breast cancers(Azimi et al. 2017; Pan et al. 2017). In this work, bioinformatics analysis revealed obviously increased expression levels of SPP1 and SERPINE1 in LSCC tissues, which led to poor clinical outcomes. We also proved that SPP1 and SERPINE1 were highly expressed in LSCC cells and that LSCC cell proliferation, invasion and migration were suppressed when SPP1 and SERPINE1 were knocked out. 

cytokine that plays as a chemotactic factor, mainly for leukocytes(Waugh \& Wilson 2008).

352

353 Although the specific mechanisms underlying CXCL8-mediated cancer progression may be diverse, CXCL8 has been identified to participate in various cancers(Shrivastava et al. 2014). Our results also verify that highly expressed CXCL-8 can enhance the tumorigenesis and invasion of LSCC. OSM (oncostatin M), a member of the inflammatory gp130 cytokine family, has been contained to be involved in cancer invasion and metastasis(West et al. 2017). Although limited studies have addressed the role of OSM in LSCC, OSM, as a pleiotropic cytokine, has been shown to function in a variety of cancer cells in vitro, specifically to (1) promote a stem cell-like phenotype and epithelial-to-mesenchymal transition (EMT)(Junk et al. 2017; West et al. 2014); (2) induce the expression of hypoxia inducible factor-1 $\alpha$, VEGF, and other proangiogenic factors(Fossey et al. 2011; Vollmer et al. 2009); and (3) promote tumour cell invasion and metastasis(Holzer et al. 2004). COL1A1 (collagen type I alpha 1), a major element of the extracellular matrix and connective tissues, has been discovered to be actively associated with tumour size and depth of invasion in gastric cancer(Yu et al. 2020). Additionally, research on oesophageal squamous cell carcinoma indicated that COL1A1 might be of vital importance in migration, invasion and progression, and its function may be mediated via the $\mathrm{PI} 3 \mathrm{~K} / \mathrm{Akt} / \mathrm{mTOR}$ pathway, p53 pathway, apoptotic pathway and cell cycle(Li et al. 2019).

\section{Conclusions}

In summary, bioinformatics analysis identified hub genes and pathways that may play central roles in the occurrence, development and prognosis of LSCC. MMP9, SPP1, SERPINE1, MMP1, MMP13, MMP3, CXCL8, OSM, and COL1A1, the hub genes of LSCC, may serve vital functions in the diagnosis and treatment of LSCC, and SPP1, SERPINE1 and MMP1 may be linked with poor prognosis in LSCC patients. We demonstrated that SPP1, SERPINE1 and MMP1 were upregulated in LSCC cells and related to LSCC cell proliferation, invasion and 
376

377

378

379

380

381

382

383

384

386

387

388

389

390

391

392

393

394

395

396

397

398

399

400

401

402

403

migration.

\section{Acknowledgements}

This work was supported by the Hebei Medical Research Youth Program [20200175].

\section{Ethics approval and consent to participate}

Not applicable.

\section{Competing interests}

The authors declare that they have no competing interests.

\section{References}

Ashburner M, Ball CA, Blake JA, Botstein D, Butler H, Cherry JM, Davis AP, Dolinski K, Dwight SS, Eppig JT, Harris MA, Hill DP, Issel-Tarver L, Kasarskis A, Lewis S, Matese JC, Richardson JE, Ringwald M, Rubin GM, and Sherlock G. 2000. Gene ontology: tool for the unification of biology. The Gene Ontology Consortium. Nature genetics 25:25-29.

Assidi M, Gomaa W, Jafri M, Hanbazazh M, Al-Ahwal M, Pushparaj P, Al-Harbi A, Al-Qahtani M, Buhmeida A, and Al-Maghrabi J. 2019. Prognostic value of Osteopontin (SPP1) in colorectal carcinoma requires a personalized molecular approach. Tumour biology : the journal of the International Society for Oncodevelopmental Biology and Medicine 41:1010428319863627. 10.1177/1010428319863627

Azimi I, Petersen RM, Thompson EW, Roberts-Thomson SJ, and Monteith GR. 2017. Hypoxia-induced reactive oxygen species mediate $\mathrm{N}$-cadherin and SERPINE1 expression, EGFR signalling and motility in MDA-MB468 breast cancer cells. Scientific reports 7:15140. 10.1038/s41598-017-15474-7

Bandettini WP, Kellman P, Mancini C, Booker OJ, Vasu S, Leung SW, Wilson JR, Shanbhag SM, Chen MY, and Arai AE. 2012. MultiContrast Delayed Enhancement (MCODE) improves detection of subendocardial myocardial infarction by late gadolinium enhancement cardiovascular magnetic resonance: a clinical validation study. Journal of cardiovascular magnetic resonance : official journal of the Society for Cardiovascular Magnetic Resonance 14:83. 10.1186/1532-429x-14-83 
404

405

406

407

408

409

410

411

412

413

414

415

416

417

418

419

420

421

422

423

424

425

426

427

428

429

430

431

432

433

434

435

436

437

438

439

440

441

442

443

Barrett T, Wilhite SE, Ledoux P, Evangelista C, Kim IF, Tomashevsky M, Marshall KA, Phillippy KH, Sherman PM, Holko M, Yefanov A, Lee H, Zhang N, Robertson CL, Serova N, Davis S, and Soboleva A. 2013. NCBI GEO: archive for functional genomics data sets--update. Nucleic acids research 41:D991-D995. 10.1093/nar/gks1193

Chandrashekar DS, Bashel B, Balasubramanya SAH, Creighton CJ, Ponce-Rodriguez I, Chakravarthi BVSK, and Varambally S. 2017. UALCAN: A Portal for Facilitating Tumor Subgroup Gene Expression and Survival Analyses. Neoplasia (New York, NY) 19:649-658. 10.1016/j.neo.2017.05.002

Chin C-H, Chen S-H, Wu H-H, Ho C-W, Ko M-T, and Lin C-Y. 2014. cytoHubba: identifying hub objects and subnetworks from complex interactome. BMC systems biology 8 Suppl 4:S11. 10.1186/1752-0509-8-s4-s11

Chrysovergis A, Papanikolaou V, Tsiambas E, Stavraka C, Ragos V, Peschos D, Psyrri A, Mastronikolis N, and Kyrodimos E. 2019. P53/MDM2 Co-Expression in Laryngeal Squamous Cell Carcinoma Based on Digital Image Analysis. Anticancer research 39:4137-4142. 10.21873/anticanres.13572

Cossu AM, Mosca L, Zappavigna S, Misso G, Bocchetti M, De Micco F, Quagliuolo L, Porcelli M, Caraglia M, and Boccellino M. 2019. Long Non-coding RNAs as Important Biomarkers in Laryngeal Cancer and Other Head and Neck Tumours. International journal of molecular sciences 20. 10.3390/ijms20143444

Cui L, Qu C, and Liu H. 2019. Association study of cell cycle proteins and human papillomavirus in laryngeal cancer in Chinese population. Clinical otolaryngology : official journal of ENT-UK ; official journal of Netherlands Society for Oto-Rhino-Laryngology \& Cervico-Facial Surgery 44:323-329. 10.1111/coa.13296

Culhaci N, Metin K, Copcu E, and Dikicioglu E. 2004. Elevated expression of MMP-13 and TIMP-1 in head and neck squamous cell carcinomas may reflect increased tumor invasiveness. BMC cancer 4:42.

D'Souza G, Westra WH, Wang SJ, van Zante A, Wentz A, Kluz N, Rettig E, Ryan WR, Ha PK, Kang H, Bishop J, Quon H, Kiess AP, Richmon JD, Eisele DW, and Fakhry C. 2017. Differences in the Prevalence of Human Papillomavirus (HPV) in Head and Neck Squamous Cell Cancers by Sex, Race, Anatomic Tumor Site, and HPV Detection Method. JAMA oncology 3:169-177. 10.1001/jamaoncol.2016.3067

Davis S, and Meltzer PS. 2007. GEOquery: a bridge between the Gene Expression Omnibus (GEO) and BioConductor. Bioinformatics (Oxford, England) 23:1846-1847.

Ding Z, Wu C-J, Chu GC, Xiao Y, Ho D, Zhang J, Perry SR, Labrot ES, Wu X, Lis R, Hoshida Y, Hiller D, Hu B, Jiang S, Zheng H, Stegh AH, Scott KL, Signoretti S, Bardeesy N, Wang YA, Hill DE, Golub TR, Stampfer MJ, Wong WH, Loda M, Mucci L, Chin L, and DePinho RA. 2011. SMAD4-dependent barrier constrains prostate cancer growth and metastatic progression. Nature 470:269-273. 10.1038/nature09677

Fossey SL, Bear MD, Kisseberth WC, Pennell M, and London CA. 2011. Oncostatin M promotes STAT3 activation, VEGF production, and invasion in osteosarcoma cell lines. BMC cancer 11:125. 10.1186/1471-2407-11-125

Gheit T, Abedi-Ardekani B, Carreira C, Missad CG, Tommasino M, and Torrente MC. 2014. Comprehensive analysis of HPV expression in laryngeal squamous cell carcinoma. Journal of medical virology 86:642-646. 10.1002/jmv.23866

Grossman M, Ben-Chetrit N, Zhuravlev A, Afik R, Bassat E, Solomonov I, Yarden Y, and Sagi I. 2016. Tumor Cell Invasion Can Be Blocked by Modulators of Collagen Fibril Alignment That Control Assembly of the Extracellular Matrix. Cancer research 76:4249-4258. 10.1158/0008-5472.can-15-2813

Grzelczyk WL, Szemraj J, and Józefowicz-Korczyńska M. 2016. The matrix metalloproteinase in larynx cancer. Postepy higieny i medycyny doswiadczalnej (Online) 70:1190-1197.

Peer] reviewing PDF | (2020:11:55543:1:2:CHECK 9 Mar 2021) 
444

445

446

447

448

449

450

451

452

453

454

455

456

457

458

459

460

461

462

463

464

465

466

467

468

469

470

471

472

473

474

475

476

477

478

479

480

481

482

483

Han X, Wang W, He J, Jiang L, and Li X. 2019. Osteopontin as a biomarker for osteosarcoma therapy and prognosis. Oncology letters 17:2592-2598. 10.3892/ol.2019.9905

He G, Yao W, Li L, Wu Y, Feng G, and Chen L. 2020. LOXL1-AS1 contributes to the proliferation and migration of laryngocarcinoma cells through miR-589-5p/TRAF6 axis. Cancer cell international 20:504. 10.1186/s12935020-01565-5

Hermida-Prado F, Granda-Díaz R, Del-Río-lbisate N, Villaronga MÁ, Allonca E, Garmendia I, Montuenga LM, Rodríguez R, Vallina A, Alvarez-Marcos C, Rodrigo JP, and García-Pedrero JM. 2019. The Differential Impact of SRC Expression on the Prognosis of Patients with Head and Neck Squamous Cell Carcinoma. Cancers 11. 10.3390/cancers11111644

Holmås S, Puig RR, Acencio ML, Mironov V, and Kuiper M. 2019. The Cytoscape BioGateway App: explorative network building from the BioGateway triple store. Bioinformatics (Oxford, England). 10.1093/bioinformatics/btz835

Holzer RG, Ryan RE, Tommack M, Schlekeway E, and Jorcyk CL. 2004. Oncostatin M stimulates the detachment of a reservoir of invasive mammary carcinoma cells: role of cyclooxygenase-2. Clinical \& experimental metastasis 21:167-176.

Huang DW, Sherman BT, Tan Q, Collins JR, Alvord WG, Roayaei J, Stephens R, Baseler MW, Lane HC, and Lempicki RA. 2007. The DAVID Gene Functional Classification Tool: a novel biological module-centric algorithm to functionally analyze large gene lists. Genome biology 8:R183.

Hunter FW, Young RJ, Shalev Z, Vellanki RN, Wang J, Gu Y, Joshi N, Sreebhavan S, Weinreb I, Goldstein DP, Moffat J, Ketela T, Brown KR, Koritzinsky M, Solomon B, Rischin D, Wilson WR, and Wouters BG. 2015. Identification of P450 Oxidoreductase as a Major Determinant of Sensitivity to Hypoxia-Activated Prodrugs. Cancer research 75:4211-4223. 10.1158/0008-5472.can-15-1107

Jemal A, Siegel R, Ward E, Murray T, Xu J, and Thun MJ. 2007. Cancer statistics, 2007. CA: a cancer journal for clinicians 57:43-66.

Johnson KCC, Ley J, Oppelt P, Lu J, Gay HA, Daly M, Jackson R, Rich J, Pipkorn P, Paniello RC, Zevallos J, Thorstad W, and Adkins DR. 2019. nab-Paclitaxel-based induction chemotherapy followed by cisplatin and radiation therapy for human papillomavirus-unrelated head and neck squamous-cell carcinoma. Medical oncology (Northwood, London, England) 36:93. 10.1007/s12032-019-1318-5

Junk DJ, Bryson BL, Smigiel JM, Parameswaran N, Bartel CA, and Jackson MW. 2017. Oncostatin M promotes cancer cell plasticity through cooperative STAT3-SMAD3 signaling. Oncogene 36:4001-4013. 10.1038/onc.2017.33

Kalfert D, Ludvikova M, Topolcan O, Windrichova J, Malirova E, Pesta M, and Celakovsky P. 2014. Analysis of preoperative serum levels of MMP1, -2 , and -9 in patients with site-specific head and neck squamous cell cancer. Anticancer research 34:7431-7441.

Kanehisa M, Sato Y, Kawashima M, Furumichi M, and Tanabe M. 2016. KEGG as a reference resource for gene and protein annotation. Nucleic acids research 44:D457-D462. 10.1093/nar/gkv1070

Katiyar T, Maurya SS, Hasan F, Singh AP, Khan AJ, Hadi R, Singh S, Bhatt MLB, and Parmar D. 2017. Association of cytochrome P450 1B1 haplotypes with head and neck cancer risk. Environmental and molecular mutagenesis 58:443-450. 10.1002/em.22098

Kim Y, Nam HJ, Lee J, Park DY, Kim C, Yu YS, Kim D, Park SW, Bhin J, Hwang D, Lee H, Koh GY, and Baek SH. 2016.

Peer) reviewing PDF | (2020:11:55543:1:2:CHECK 9 Mar 2021) 
484

485

486

487

488

489

490

491

492

493

494

495

496

497

498

499

500

501

502

503

504

505

506

507

508

509

510

511

512

513

514

515

516

517

518

519

520

521

522

523

Methylation-dependent regulation of HIF-1 $\alpha$ stability restricts retinal and tumour angiogenesis. Nature communications 7:10347. 10.1038/ncomms10347

Krecicki T, Fraczek M, Jelen M, Podhorska M, Szkudlarek T, and Zatonski T. 2003. Expression of collagenase-1 (MMP-1), collagenase-3 (MMP-13) and tissue inhibitor of matrix metalloproteinase-1 (TIMP-1) in laryngeal squamous cell carcinomas. European archives of oto-rhino-laryngology : official journal of the European Federation of Oto-Rhino-Laryngological Societies (EUFOS) : affiliated with the German Society for OtoRhino-Laryngology - Head and Neck Surgery 260:494-497.

Li J, Wang X, Zheng K, Liu Y, Li J, Wang S, Liu K, Song X, Li N, Xie S, and Wang S. 2019. The clinical significance of collagen family gene expression in esophageal squamous cell carcinoma. PeerJ 7:e7705. 10.7717/peerj.7705

Liu C, Zhang S, Ma G, Liang J, and Hu J. 2011. [Expression of matrix metalloproteinase-1, E26 transformationspecific-1 in laryngeal carcinoma tissue and the clinical significance]. Lin chuang er bi yan hou tou jing wai ke za zhi = Journal of clinical otorhinolaryngology, head, and neck surgery 25:1111-1114.

Liu G, Ren F, and Song Y. 2019. Upregulation of SPOCK2 inhibits the invasion and migration of prostate cancer cells by regulating the MT1-MMP/MMP2 pathway. PeerJ 7:e7163. 10.7717/peerj.7163

Ma H, Du X, Zhang S, Wang Q, Yin Y, Qiu X, Da P, Yue H, Wu H, and Xu F. 2017. Achaete-scute complex homologue1 promotes development of laryngocarcinoma via facilitating the epithelial-mesenchymal transformation. Tumour biology : the journal of the International Society for Oncodevelopmental Biology and Medicine 39:1010428317705752. 10.1177/1010428317705752

Matulka M, Konopka A, Mroczko B, Pryczynicz A, Kemona A, Groblewska M, Sieskiewicz A, and Olszewska E. 2019. Expression and Concentration of Matrix Metalloproteinase 9 and Tissue Inhibitor of Matrix Metalloproteinases 1 in Laryngeal Squamous Cell Carcinoma. Disease markers 2019:3136792. $10.1155 / 2019 / 3136792$

Mishra M, Tiwari S, and Gomes AV. 2017. Protein purification and analysis: next generation Western blotting techniques. Expert review of proteomics 14:1037-1053. 10.1080/14789450.2017.1388167

Pan J-X, Qu F, Wang F-F, Xu J, Mu L-S, Ye L-Y, and Li J-J. 2017. Aberrant SERPINE1 DNA methylation is involved in carboplatin induced epithelial-mesenchymal transition in epithelial ovarian cancer. Archives of gynecology and obstetrics 296:1145-1152. 10.1007/s00404-017-4547-x

Patel SA, Qureshi MM, Dyer MA, Jalisi S, Grillone G, and Truong MT. 2019. Comparing surgical and nonsurgical larynx-preserving treatments with total laryngectomy for locally advanced laryngeal cancer. Cancer 125:3367-3377. 10.1002/cncr.32292

Pavón MA, Arroyo-Solera I, Céspedes MV, Casanova I, León X, and Mangues R. 2016. UPA/UPAR and SERPINE1 in head and neck cancer: role in tumor resistance, metastasis, prognosis and therapy. Oncotarget 7:5735157366. 10.18632/oncotarget.10344

Ragos V, S Mastronikolis N, Tsiambas E, Baliou E, N Mastronikolis S, Tsoukalas N, E Patsouri E, and P Fotiades P. 2018. p53 mutations in oral cavity carcinoma. Journal of BUON : official journal of the Balkan Union of Oncology 23:1569-1572.

Rydlova M, Holubec L, Ludvikova M, Kalfert D, Franekova J, and Povysil C. 2008. Biological activity and clinical implications of the matrix metalloproteinases. Anticancer research 28:1389-1397.

Shen J, Yu S, Sun X, Yin M, Fei J, and Zhou J. 2019. Identification of key biomarkers associated with development 
524

525

526

527

528

529

530

531

532

533

534

535

536

537

538

539

540

541

542

543

544

545

546

547

548

549

550

551

552

553

554

555

556

557

558

559

560

561

562

563 and prognosis in patients with ovarian carcinoma: evidence from bioinformatic analysis. Journal of ovarian research 12:110. 10.1186/s13048-019-0578-1

Shrivastava MS, Hussain Z, Giricz O, Shenoy N, Polineni R, Maitra A, and Verma A. 2014. Targeting chemokine pathways in esophageal adenocarcinoma. Cell cycle (Georgetown, Tex) 13:3320-3327.

10.4161/15384101.2014.968426

Szklarczyk D, Franceschini A, Wyder S, Forslund K, Heller D, Huerta-Cepas J, Simonovic M, Roth A, Santos A, Tsafou KP, Kuhn M, Bork P, Jensen LJ, and von Mering C. 2015. STRING v10: protein-protein interaction networks, integrated over the tree of life. Nucleic acids research 43:D447-D452. 10.1093/nar/gku1003

Tang Z, Li C, Kang B, Gao G, Li C, and Zhang Z. 2017. GEPIA: a web server for cancer and normal gene expression profiling and interactive analyses. Nucleic acids research 45. 10.1093/nar/gkx247

Tinker AV, Boussioutas A, and Bowtell DDL. 2006. The challenges of gene expression microarrays for the study of human cancer. Cancer cell 9:333-339.

Vollmer S, Kappler V, Kaczor J, Flügel D, Rolvering C, Kato N, Kietzmann T, Behrmann I, and Haan C. 2009. Hypoxiainducible factor 1 alpha is up-regulated by oncostatin $\mathrm{M}$ and participates in oncostatin $\mathrm{M}$ signaling. Hepatology (Baltimore, Md) 50:253-260. 10.1002/hep.22928

Wang H-T, Yang Y-C, Mao X, Wang Y, and Huang R. 2018. Cytotoxic gelsedine-type indole alkaloids from Gelsemium elegans. Journal of Asian natural products research 20:321-327.

10.1080/10286020.2017.1342637

Waugh DJJ, and Wilson C. 2008. The interleukin-8 pathway in cancer. Clinical cancer research : an official journal of the American Association for Cancer Research 14:6735-6741. 10.1158/1078-0432.ccr-07-4843

West NR, Hegazy AN, Owens BMJ, Bullers SJ, Linggi B, Buonocore S, Coccia M, Görtz D, This S, Stockenhuber K, Pott J, Friedrich M, Ryzhakov G, Baribaud F, Brodmerkel C, Cieluch C, Rahman N, Müller-Newen G, Owens RJ, Kühl AA, Maloy KJ, Plevy SE, Keshav S, Travis SPL, and Powrie F. 2017. Oncostatin M drives intestinal inflammation and predicts response to tumor necrosis factor-neutralizing therapy in patients with inflammatory bowel disease. Nature medicine 23:579-589. 10.1038/nm.4307

West NR, Murray JI, and Watson PH. 2014. Oncostatin-M promotes phenotypic changes associated with mesenchymal and stem cell-like differentiation in breast cancer. Oncogene 33:1485-1494. 10.1038/onc.2013.105

Wilhelm J, and Pingoud A. 2003. Real-time polymerase chain reaction. Chembiochem : a European journal of chemical biology 4:1120-1128.

Xu J, Zhang R, and Zhao J. 2017. The Novel Long Noncoding RNA TUSC7 Inhibits Proliferation by Sponging MiR-211 in Colorectal Cancer. Cellular physiology and biochemistry : international journal of experimental cellular physiology, biochemistry, and pharmacology 41:635-644. 10.1159/000457938

Yang J, Zhou L, Zhang Y, Zheng J, Zhou J, Wei Z, and Zou J. 2019. DIAPH1 Is Upregulated and Inhibits Cell Apoptosis through ATR/p53/Caspase-3 Signaling Pathway in Laryngeal Squamous Cell Carcinoma. Disease markers 2019:6716472. 10.1155/2019/6716472

Yu C, Chen J, Ma J, Zang L, Dong F, Sun J, and Zheng M. 2020. Identification of Key Genes and Signaling Pathways Associated with the Progression of Gastric Cancer. Pathology oncology research : POR 26:1903-1919. 10.1007/s12253-019-00781-3

Zeng B, Zhou M, Wu H, and Xiong Z. 2018. SPP1 promotes ovarian cancer progression via Integrin $\beta 1 / F A K / A K T$

Peer] reviewing PDF | (2020:11:55543:1:2:CHECK 9 Mar 2021) 
564 signaling pathway. OncoTargets and therapy 11:1333-1343. 10.2147/ott.s154215

565 Zhao F, Evans K, Xiao C, DeVito N, Theivanthiran B, Holtzhausen A, Siska PJ, Blobe GC, and Hanks BA. 2018. Stromal

566 Fibroblasts Mediate Anti-PD-1 Resistance via MMP-9 and Dictate TGF $\beta$ Inhibitor Sequencing in Melanoma.

567 Cancer immunology research 6:1459-1471. 10.1158/2326-6066.cir-18-0086

568 Zhou X, and Qi Y. 2014. PLGF inhibition impairs metastasis of larynx carcinoma through MMP3 downregulation.

569 Tumour biology : the journal of the International Society for Oncodevelopmental Biology and Medicine

$570 \quad 35: 9381-9386.10 .1007 /$ s13277-014-2232-2

571 Zhou X, and Qi Y. 2015. Larynx carcinoma regulates tumor-associated macrophages through PLGF signaling.

$572 \quad$ Scientific reports 5:10071. 10.1038/srep10071

573

574 
Figure 1

Identification of DEGs in gene expression profile datasets (GSE59102 and GSE107591).

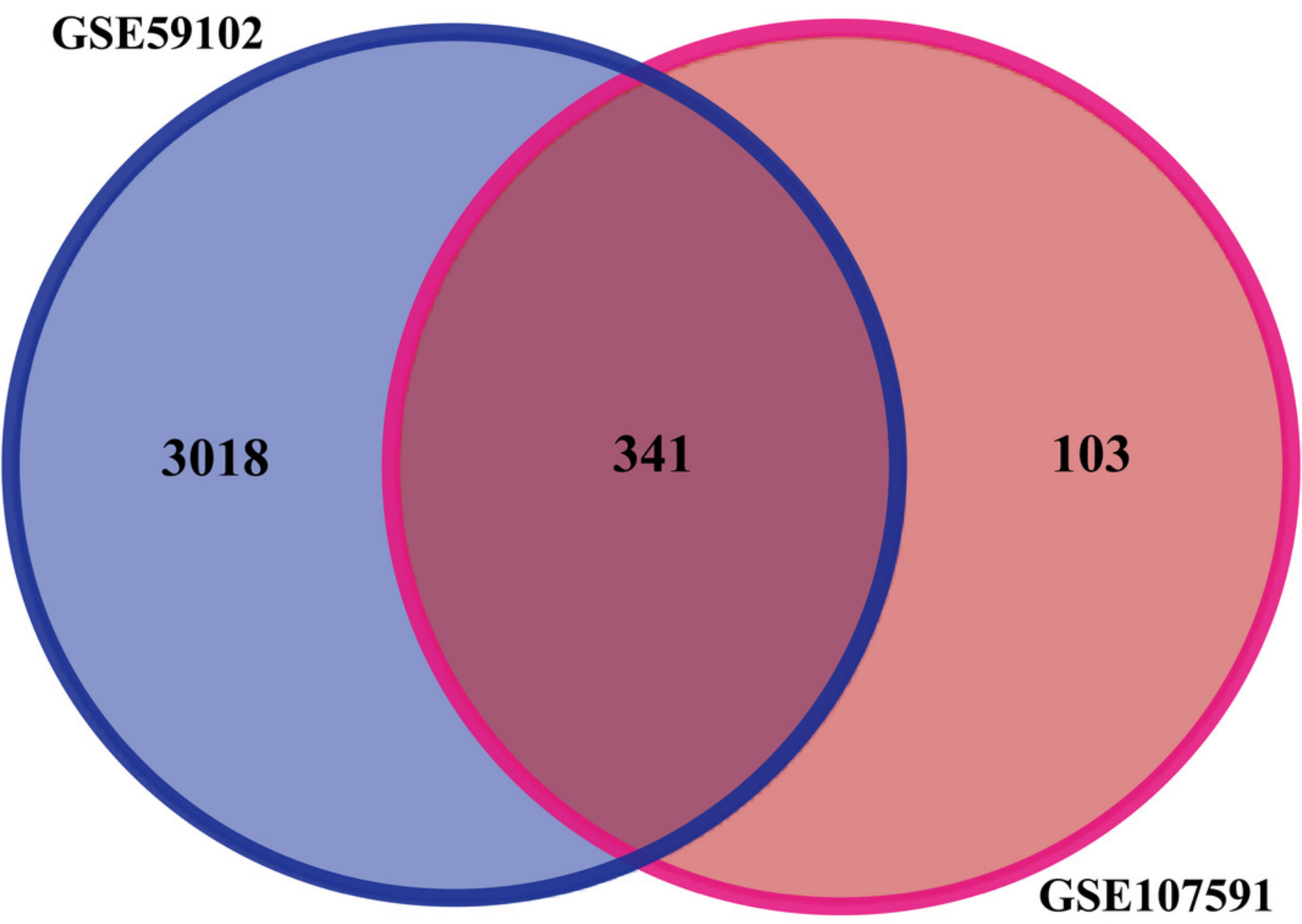


Figure 2

Common DEG PPI network construction and module analysis.

(A) A total of 235 DEGs were visualized in the DEG PPI network complex: the nodes represent proteins, and the edges represent the interactions of the proteins. (B) Module analysis using MCODE: MCODE score $>5$; degree cut-off $=2$; node score cut-off $=0.2 ;$ max depth $=100$; and $\mathrm{k}$-score $=2$.

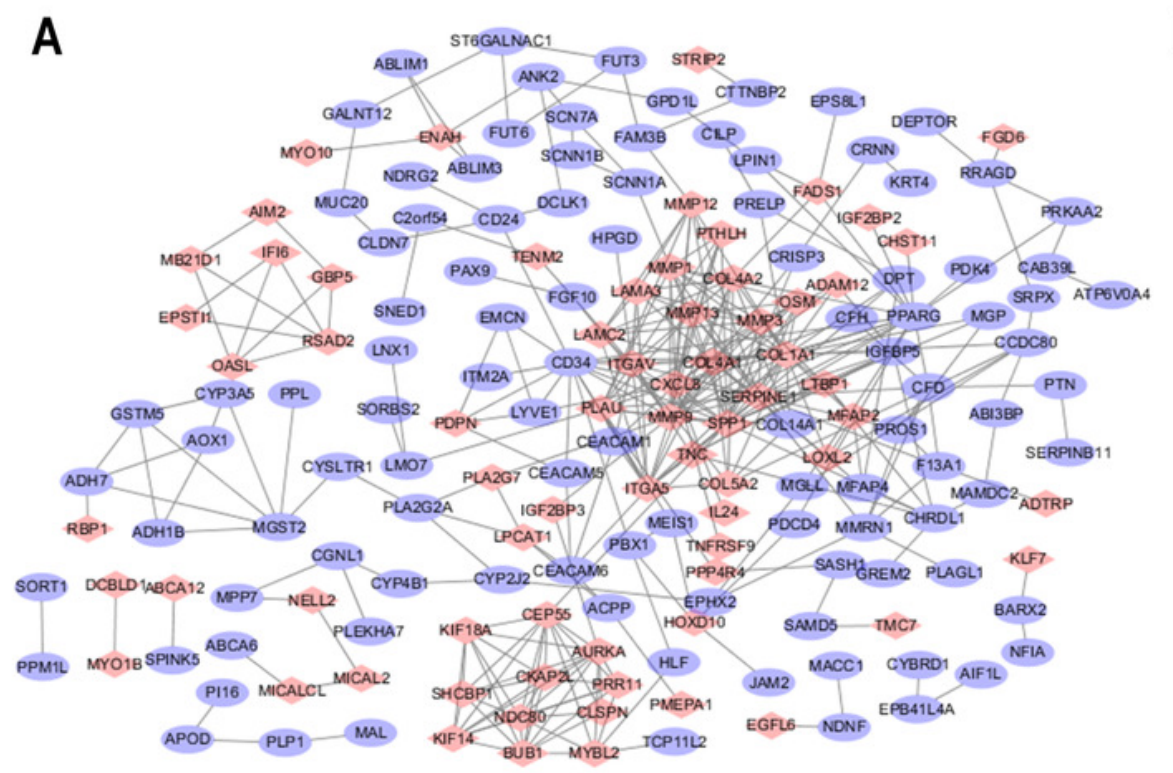

B

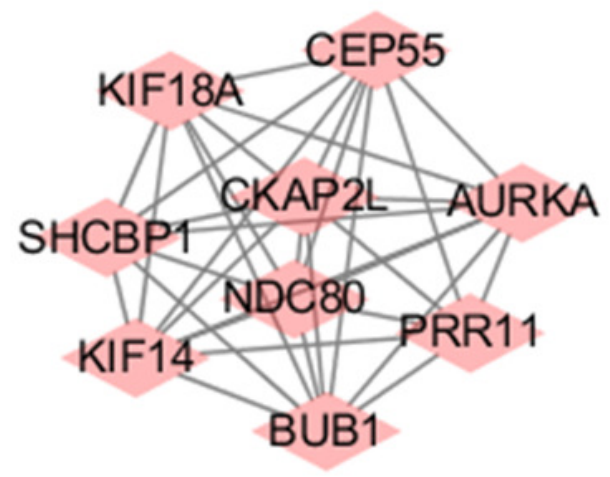


Figure 3

The expression level of hub genes between cancerous and noncancerous tissues according to the UALCAN and GEPIA databases.

(A-I) UALCAN database. (J-R) GEPIA database. 

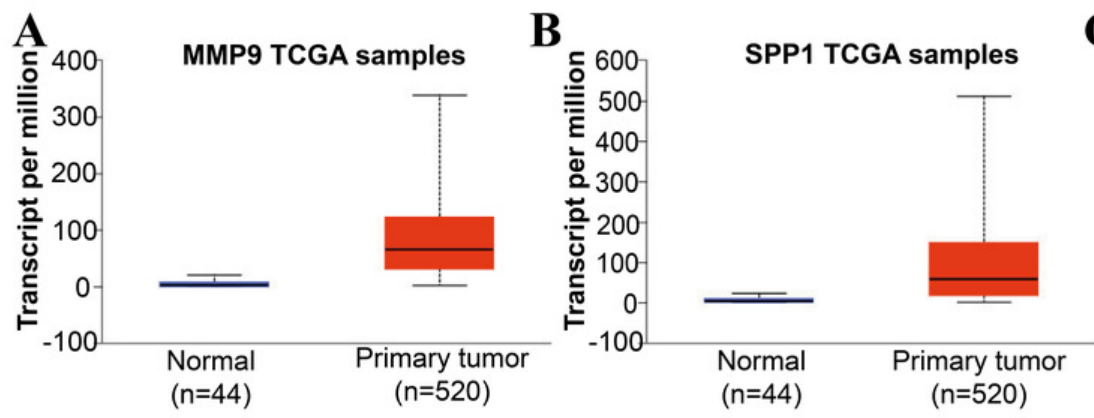

C

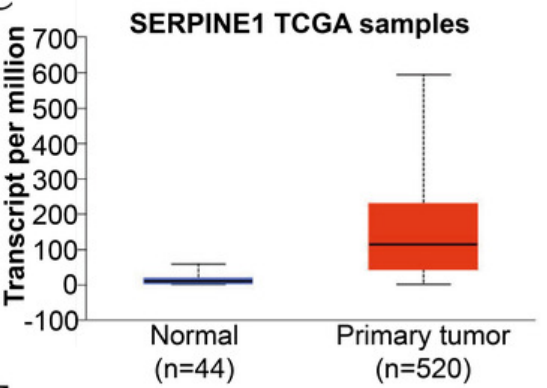

D $\mathbf{E}$

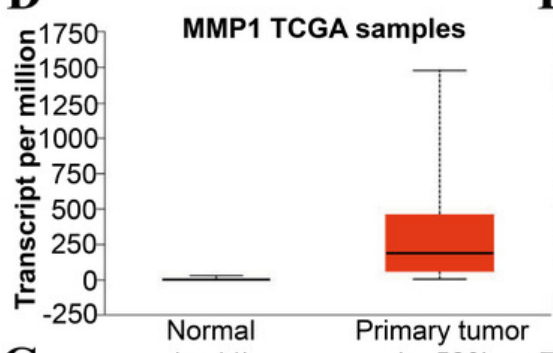

E

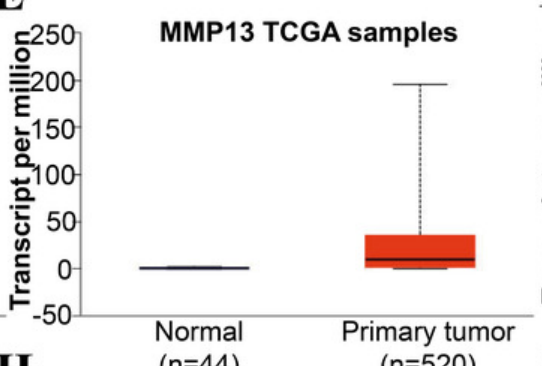

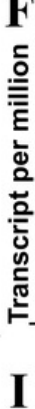
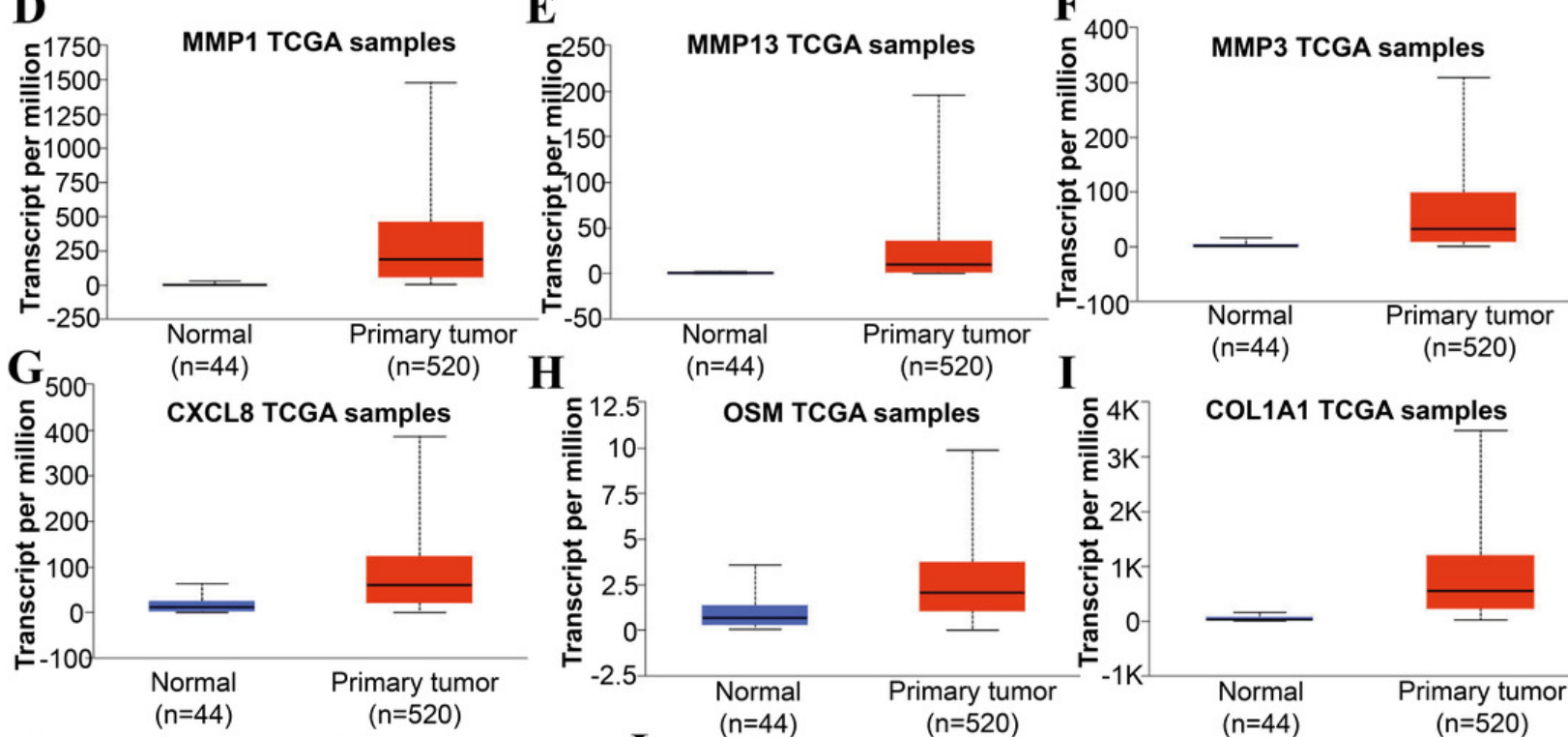

MMP3 TCGA samples
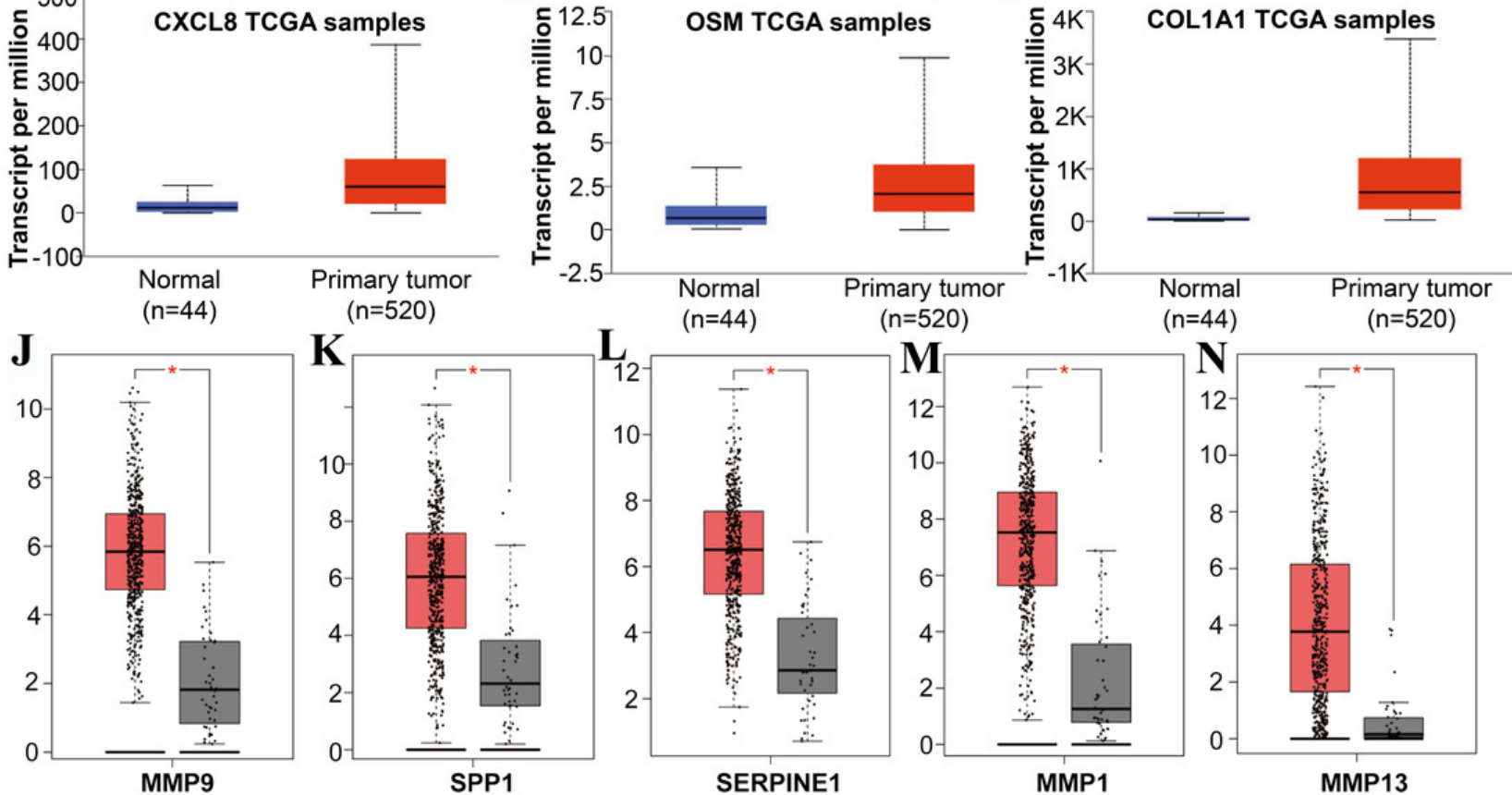

SERPINE1

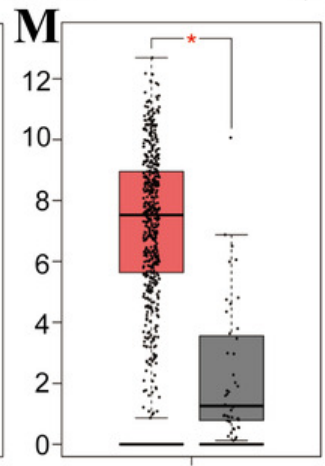

MMP1

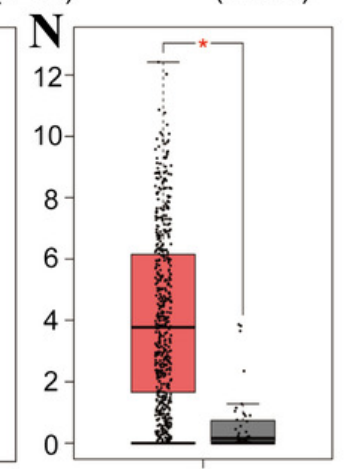

(num $(T)=519 ; \operatorname{num}(N)=44$ )
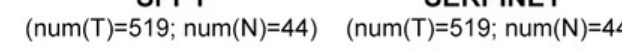

44) $(\operatorname{num}(\mathrm{T})=519 ; \operatorname{num}(\mathrm{N})=44)$

MMP13
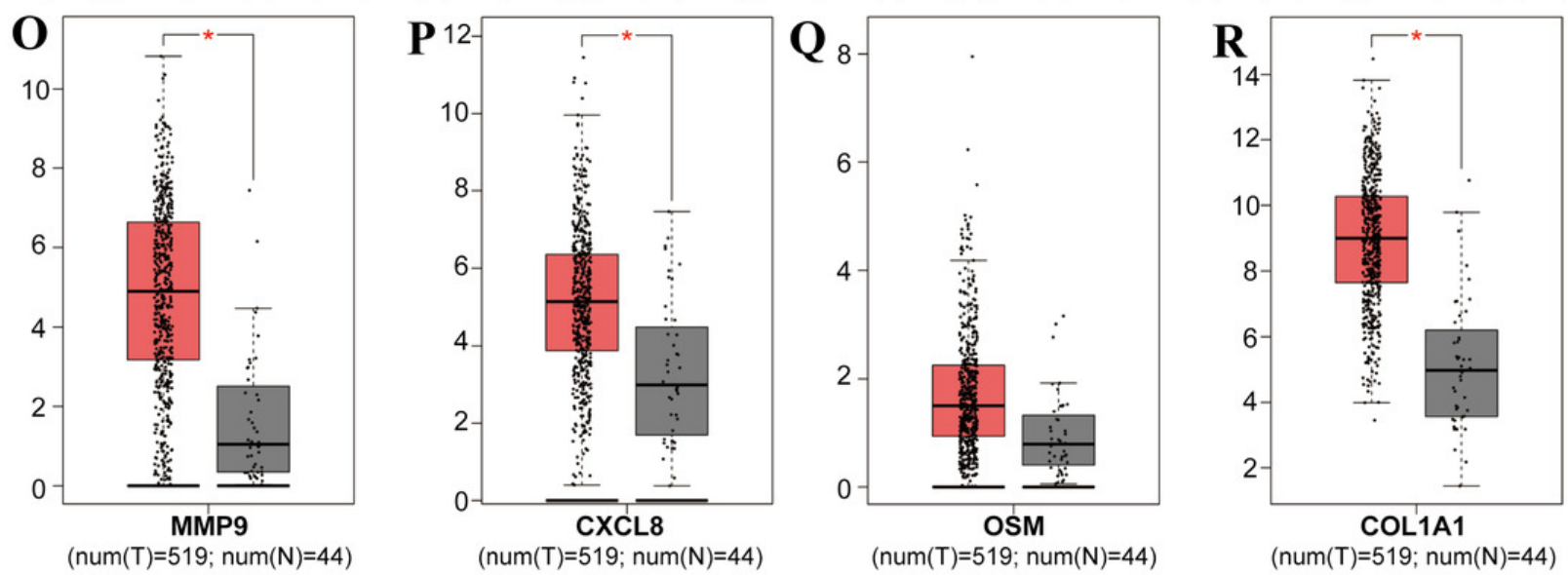

Peer] reviewing PDF | (2020:11:55543:1:2:CHECK 9 Mar 2021) 
Figure 4

The prognostic information of the nine hub genes.

(A-I) The GEPIA online tool was used to identify the prognostic value of the hub genes, and 3 of 9 were correlated with worse survival $(P<0.05)$.
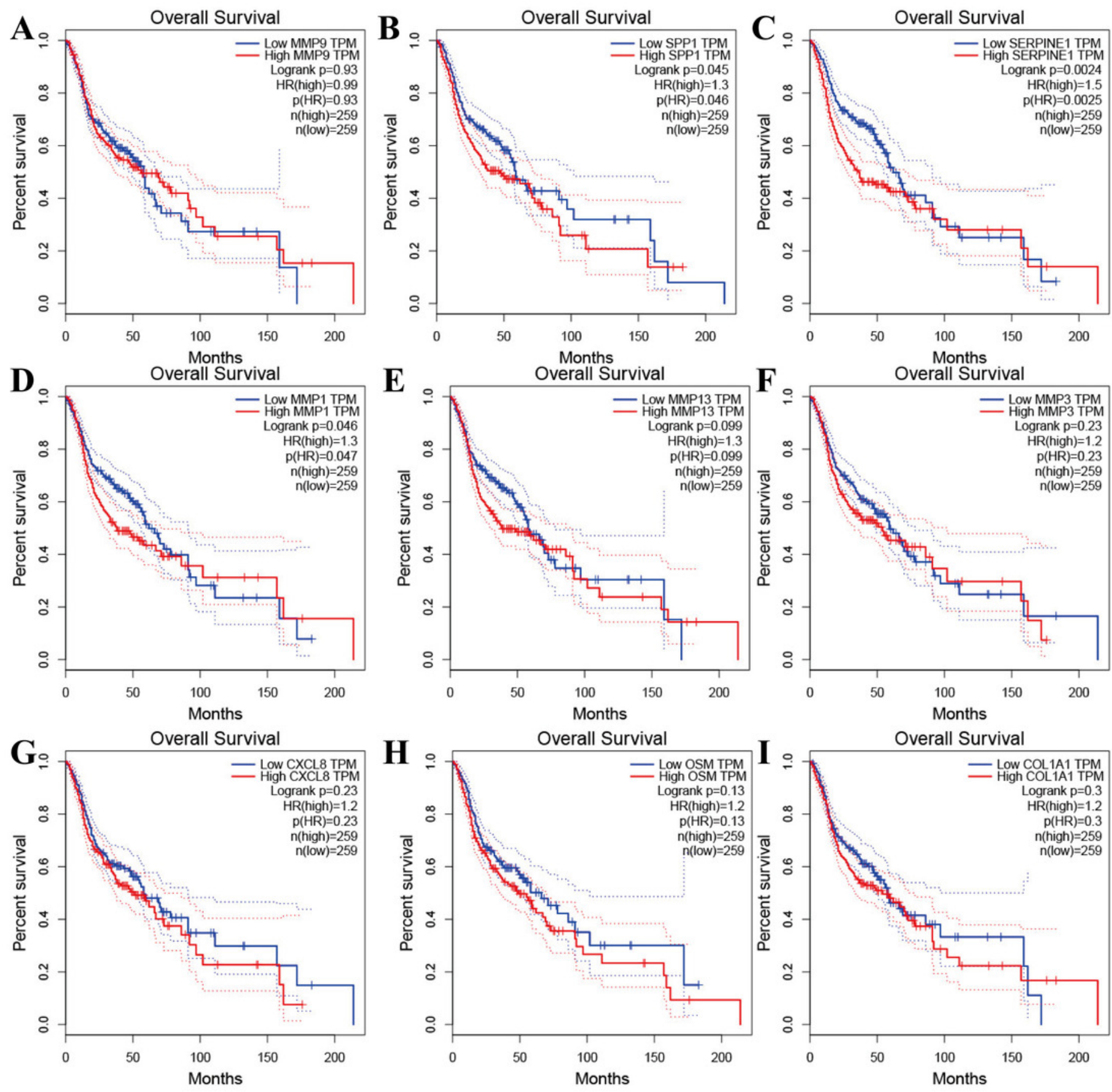


\section{Figure 5}

Expressions of SPP1, SERPINE1 and MMP1 in LSCC cells and HLEC.

(A-D) The proteins levels of SPP1, SERPINE1 and MMP1 were determined by western blotting in HLEC, LSC-1 and Hep2 cells. (E) Relative expression of SPP1, SERPINE1 and MMP1 in HLEC, Hep2 and LSC-1 cells was examined by qPCR and normalized to $\beta$-actin expression. ( ${ }^{*} p<$ $0.05, * * p<0.01, * * * p<0.001)$.

A

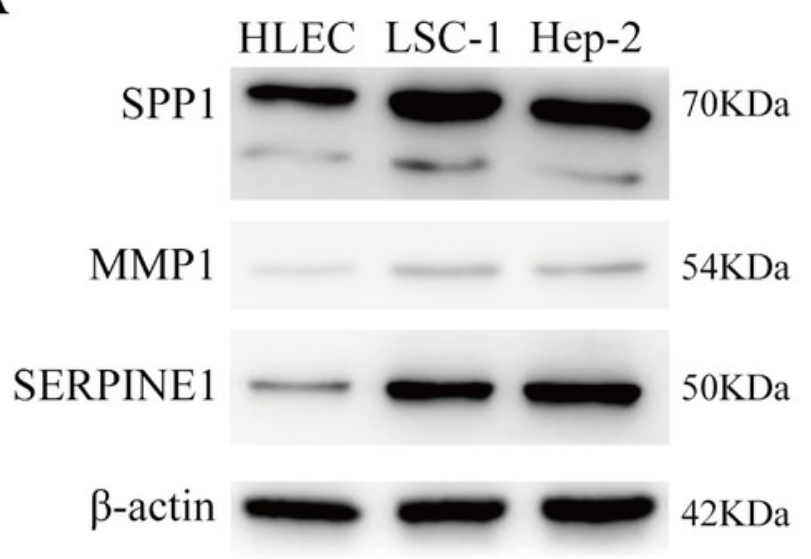

B

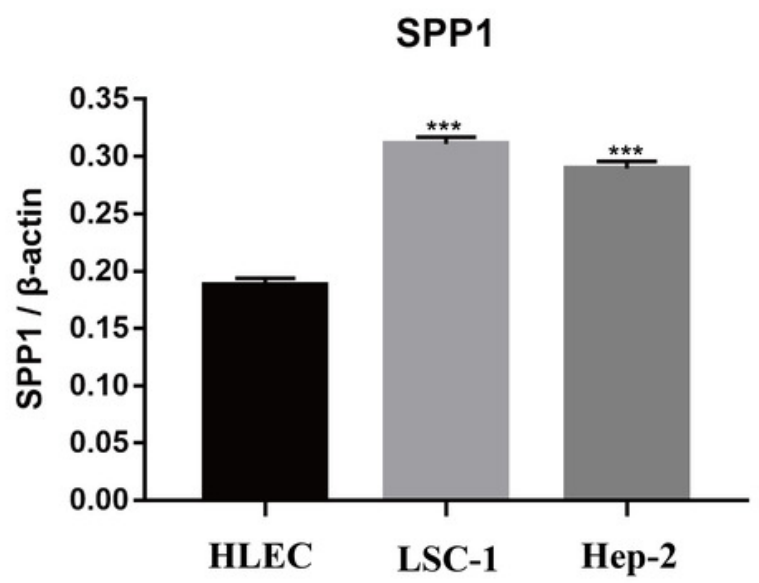

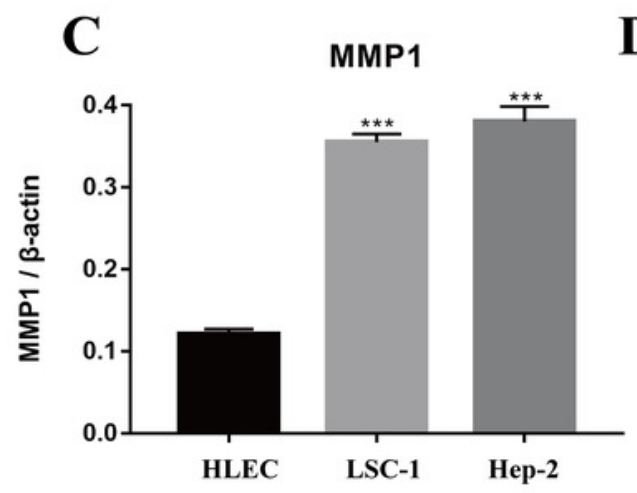

D
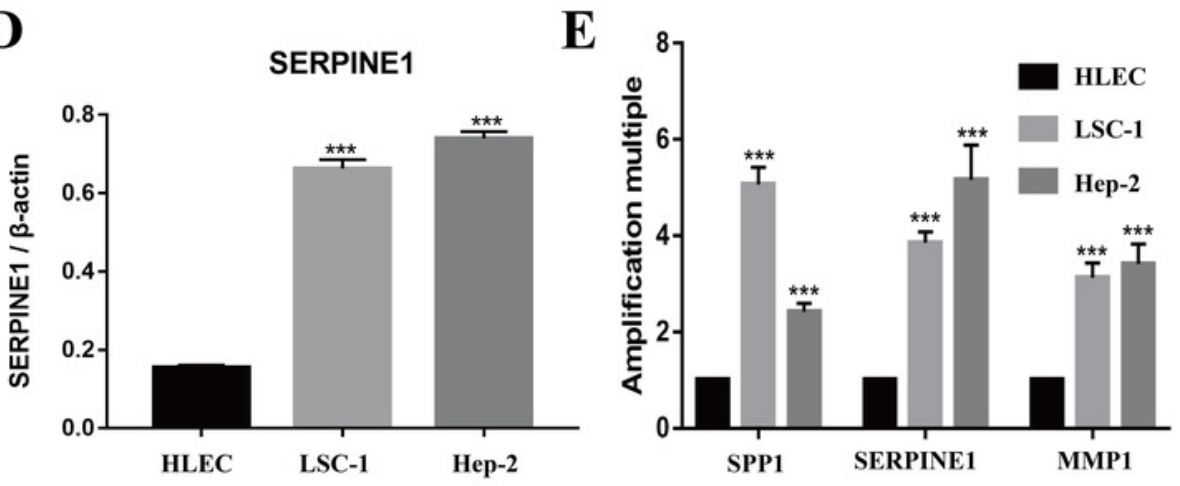
Figure 6

Effects of SPP1, SERPINE1 and MMP1 on LSCC cells proliferation in vitro.

(A) Hep2 cells (B) LSC-1 cells. ( $\left.{ }^{*} p<0.05,{ }^{* *} p<0.01,{ }^{* * *} p<0.001\right)$.

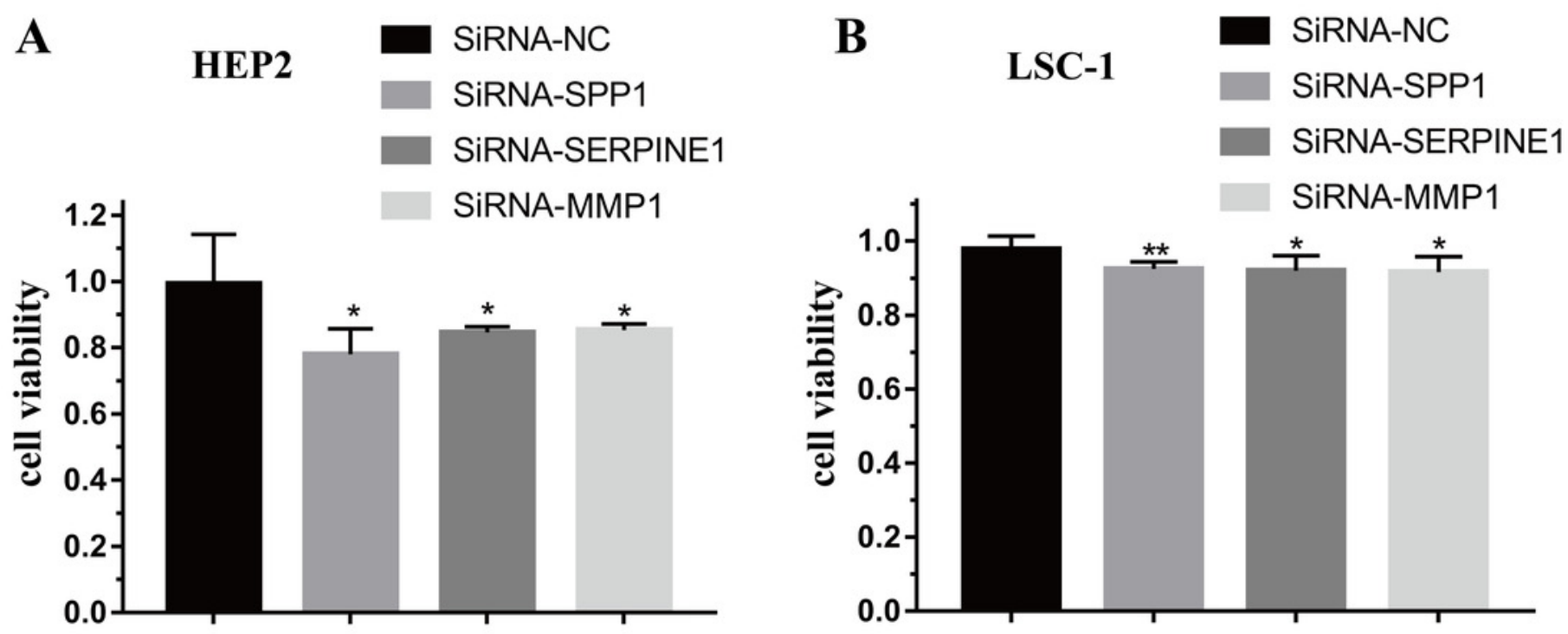




\section{Figure 7}

Effects of MMP1, SERPINE1 and SPP1 on LSCC cells migration and invasion in vitro.

(A-E) Hep2 cells were treated with SiRNA-NC, SiRNA-MMP1, SiRNA- SERPINE1 and SiRNASPP1, and the effects on cell migration and invasion were determined with cell transwell test.

(F-J) LSC-1 cells were treated with SiRNA-NC, SiRNA-MMP1, SiRNA- SERPINE1 and SiRNA-SPP1, and the effects on cell migration and invasion were determined with cell transwell test. (K) The effects on Hep2 cell migration were determined with wound healing assay. (L) The effects on LSC-1 cell migration were determined with wound healing assay. $\left({ }^{*} p<0.05,{ }^{* *} p<\right.$ $0.01, * * * p<0.001)$ 
A NC $\quad$ B SiRNA-MMP1

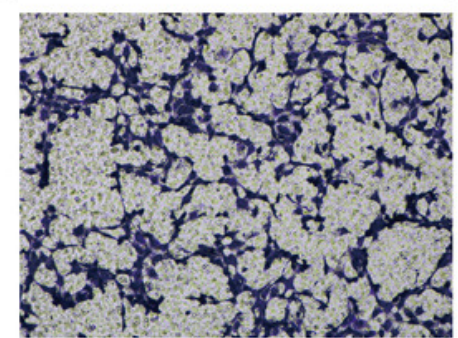

C

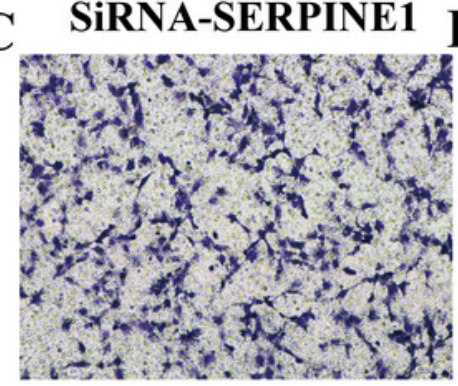

$\mathbf{F}$

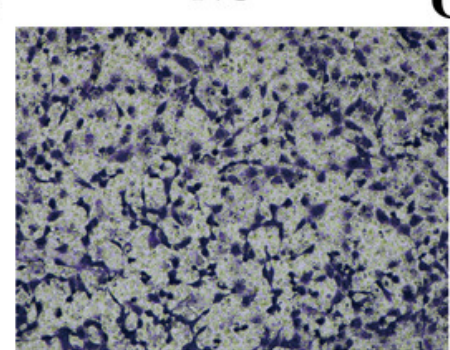

H

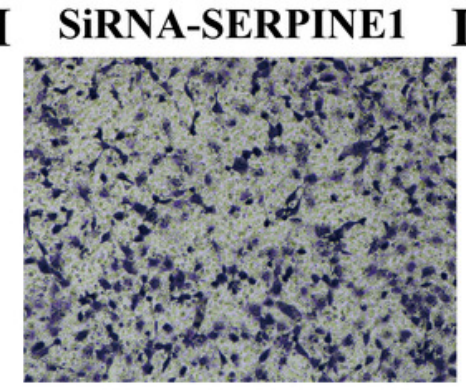

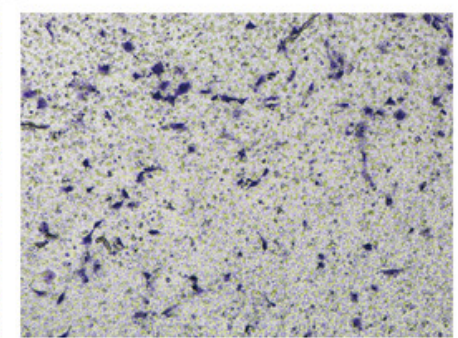

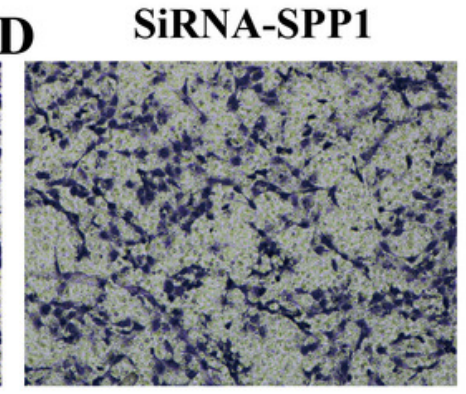

G SiRNA-MMP1

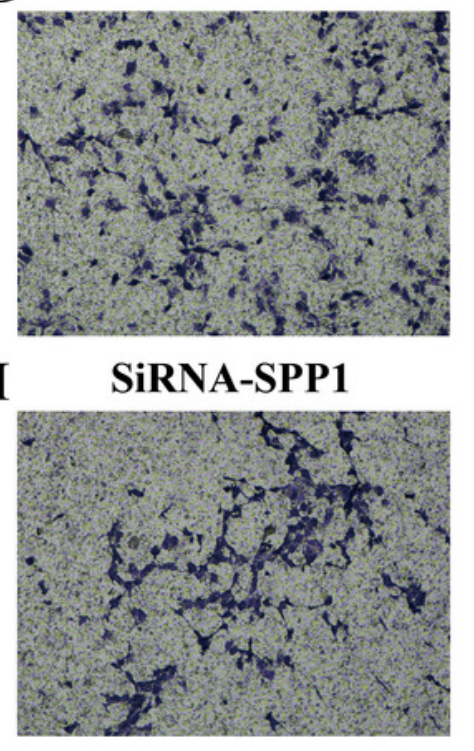

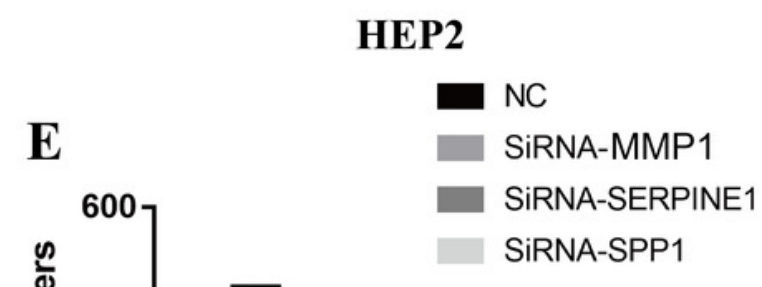

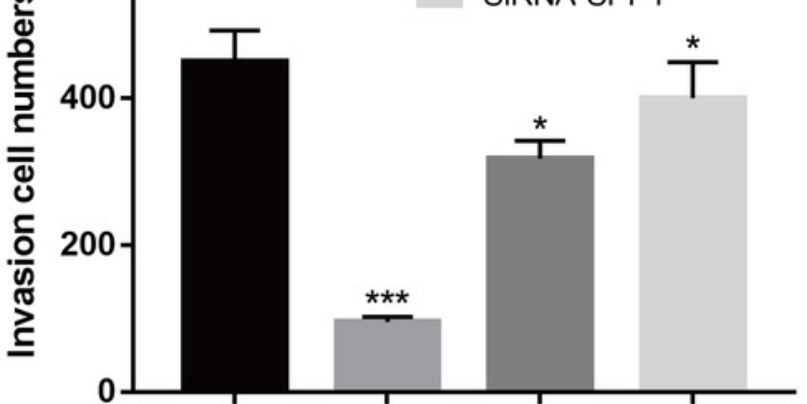

$\mathbf{K}$

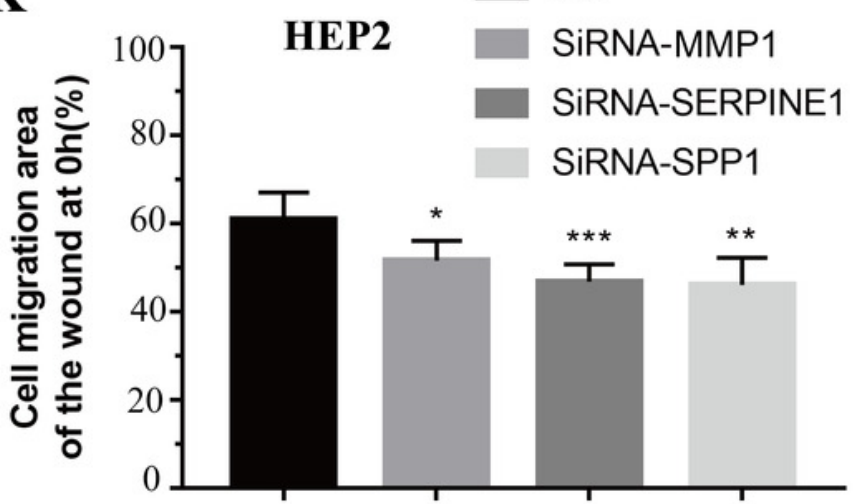

$\mathbf{L}$

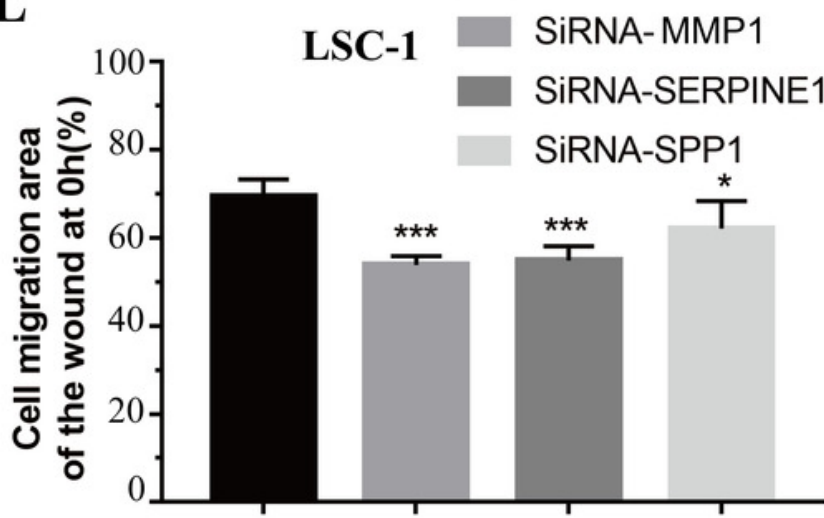


Table $\mathbf{1}$ (on next page)

Primer Sequences 
1 Table 1. Primer Sequences

\begin{tabular}{ll}
\hline Target Gene & Primer ( $\mathbf{5}^{\prime}$ to $\mathbf{3}^{\prime}$ ) \\
\hline Hu-Actin -F & CATGTACGTTGCTATCCAGGC \\
Hu-Actin-R & CTCCTTAATGTCACGCACGAT \\
Hu-SPP1-F & TGTGTTGGTGGAGGATGTC \\
Hu-SPP1-R & GCGTTTGGCTGAGAAGG \\
Hu-SERPINE1-F & GTTCATTGCTGCCCCTT \\
Hu-SERPINE1-R & CCTGGTCATGTTGCCTTT \\
Hu-MPP1-F & GAG TAT ATC TGC CAC TCC TTG \\
& AC \\
Hu-MPP1-R & CTT GGA TTG ATT TGA GAT AAG \\
& TCA TAG C \\
\hline
\end{tabular}

2 
Table 2 (on next page)

GO and KEGG pathway enrichment analysis of DEGs in LSCC samples. 
1 Table 2. GO and KEGG pathway enrichment analysis of DEGs in LSCC samples.

\begin{tabular}{lll}
\hline Pathway & Coun \\
ID & Pathway description & $\mathrm{t}^{\text {P-Value }}$
\end{tabular}

\begin{tabular}{llll}
\hline GO:00301 & extracellular matrix & 24 & $2.02 \mathrm{E}-12$ \\
98 & organization & & \\
GO:00071 & cell adhesion & 32 & $5.83 \mathrm{E}-10$ \\
55 & & &
\end{tabular}

$\begin{array}{lll}\text { GO:00305 } & \\ 74 & \text { collagen catabolic process } & 12.37 \mathrm{E}-08\end{array}$

GO:00108 positive regulation of cell-

11 substrate adhesion $\quad 8 \quad 5.50 \mathrm{E}-06$

GO:00301 collagen fibril organization $8 \quad 6.60 \mathrm{E}-06$
99

GO:00055

76

extracellular region $\quad 75 \quad 2.87 \mathrm{E}-14$

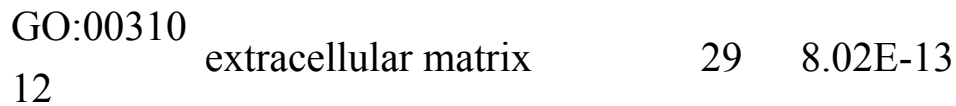

GO:00055 proteinaceous extracellular

78 matrix

$26 \quad 1.92 \mathrm{E}-11$

GO:00700 extracellular exosome $\quad 98 \quad 4.67 \mathrm{E}-11$

62

$\begin{array}{llll}\text { GO:00163 apical plasma membrane } & 18 & 2.26 \mathrm{E}-05\end{array}$

$\begin{array}{lrl}\text { GO:00082 heparin binding } & 15 \quad 1.17 \mathrm{E}-06\end{array}$

$\begin{array}{llll}\text { GO:00052 } & \text { extracellular matrix } & 8 & 1.94 \mathrm{E}-04 \\ 01 & \text { structural constituent } & \end{array}$ 


$\begin{array}{llcc}\text { hsa04512 } & \text { ECM-receptor interaction } & 13 & \text { 7.22E-08 } \\ \text { hsa00982 } & \begin{array}{l}\text { Drug metabolism - } \\ \text { cytochrome P450 }\end{array} & 10 & 4.77 \mathrm{E}-06 \\ \text { hsa04510 } & \text { Focal adhesion } & 14 & 1.38 \mathrm{E}-04 \\ \text { hsa04151 } & \begin{array}{l}\text { PI3K-Akt signaling pathway } 17 \\ \text { hsa04610 }\end{array} & \begin{array}{l}\text { Complement and coagulation } \\ \text { cascades }\end{array} & 0.0009851474\end{array}$

2 
Table 3 (on next page)

Functional enrichment analysis of DEGs in the most significant module 
1 Table 3. Functional enrichment analysis of DEGs in the most significant module

\begin{tabular}{lll}
\hline Pathway & Coun & Cothway description \\
ID & $t$ &
\end{tabular}

GO:00009 condensed nuclear chromosome

42 outer kinetochore

$2 \quad 0.001292732$

GO:00055

24

ATP binding $\quad 4 \quad 0.003547288$

GO:00085 ATP-dependent microtubule motor

74 activity, plus-end-directed

$2 \quad 0.004812021$

cfa04114 Oocyte meiosis

$2 \quad 0.016$

2 
Table 4 (on next page)

Abbreviations, official full names and synonyms for the 9 hub genes. 
1 Table 4. Abbreviations, official full names and synonyms for the 9 hub genes.

\begin{tabular}{lll}
\hline Abbreviations & Official full names & Synonyms \\
\hline MMP9 & Matrix Metallopeptidase 9 & CLG4B, GELB \\
SERPINE1 & Secreted Phosphoprotein 1 & BNSP, OPN \\
MMP1 & Matrix Metallopeptidase 1 & CLG, CLGN \\
MMP13 & Matrix Metallopeptidase 13 & Collagenase 3 \\
MMP3 & Matrix Metallopeptidase 3 & Stromelysin-1,STMY1 \\
CXCL8 & C-X-C Motif Chemokine Ligand 8IL-8 \\
OSM & Oncostatin M & Oncostatin-M \\
COL1A1 & Collagen Type I Alpha 1 Chain & Type I Proalpha 1,EDSC \\
\hline
\end{tabular}

2 